\title{
Téoros
}

Revue de recherche en tourisme

\section{Tourisme, fêtes et événements}

\section{Jacques Renaud}

Volume 5, numéro 2, juillet 1986

Tourisme, fêtes et événements

URI : https://id.erudit.org/iderudit/1080567ar

DOI : https://doi.org/10.7202/1080567ar

Aller au sommaire du numéro

Éditeur(s)

Université du Québec à Montréal

ISSN

0712-8657 (imprimé)

1923-2705 (numérique)

Découvrir la revue

Citer ce document

Renaud, J. (1986). Tourisme, fêtes et événements. Téoros, 5(2), 1-1.

https://doi.org/10.7202/1080567ar d'utilisation que vous pouvez consulter en ligne.

https://apropos.erudit.org/fr/usagers/politique-dutilisation/ 


\section{Présentation}

\section{Tourisme, fêtes et événements}

Encore une fois, Téoros innove en proposant a ses lecteurs et ses lectrices un sujet rarement traité sous cet angle.

Le Québec demeure au Canada et même en Amérique du Nord un lieu privilégié de fêtes et d'événements de toute nature qui font la joie des Québécois et des Québécoises. Ce champ d'intérét et d'intervention devient de plus en plus une "marque de commerce" qui attire chez nous le public d'ici et d'ailleurs.

Les textes qui composent ce numéro n'ont pas la prétention de faire le tour d'un sujet aussi vaste. Nous avons voulu éviter de défini, classifier et théoriser outre mesure afin de vous entraîner dans un survol rapide de ses différents aspects et ainsi, nous l'espérons, vous faire mieux connaître les réalités des fétes et événements au Québec. Ce survol n'est pas exempt cependant d'un regard critique et de quelques mises en garde et fait appel aux resultats de quelques recherches récentes.

Nous vous introduisons d'abord au sens de la fête dans ses origines comme dans sa signification d'aujourd'hui pour questionner ensuite la dimension touristique. Les conclusions $d$ 'une récente étude sur les clientèles de certains événements montréalais en surprendront plusieurs. Nous avons demandé a la Société des festivals populaires du Québec de vous présenter les fétes populaires actuelles, mais, pour être encore plus complets, nous avons pensé réunir autour d'une table ronde quelques organisateurs de fêtes et d'événements à succès: le Marathon international de Montréal, le Carnaval-Souvenir de Chicoutimi, le Festival international des feux d'artifice, le Festival d'été de Lanaudière, etc. Nous vous présentons aussi l'évolution d'un événement mondialement connu, le Carnaval de Rio.

Après avoir cerné le sens de la féte, ses manifestations contemporaines et ses liens avec le tourisme, nous avons vou/u savoir davantage comment gérer efficacement une fête ou un événement à travers son organisation, ses communications, son financement et sa mise en marché.

Outre les professeurs et étudiants universitaires, c'est plus d'une vingtaine d'organisateurs et d'organisatrices de fétes et d'événements qui ont contribué à ce numéro en nous faisant part de leurs experiences, de leurs analy. ses et de leurs méthodes qui sauront certainement vous être utiles. C'est d'ailleurs avec spontaneité et disponibilité que tous ont répondu à l'appel et nous les en remercions.
Avant de vous laisser decouvrir ce monde merveilleux des fêtes et des evenements, nous aimerions vous faire partager une réflexion émise lors de la table ronde et qui s'énonçait à peu prés comme ceci:

Le dénominateur commun du succès de toute fête ou de tout événement régional, national ou international, qu'il soit à caractère socio-culturel, socio-sportif, socio-historique, spirituel, etc.

- c'est d'avoir un produit unique qui fait appel a la créativité et à l'innovation;

- c'est d'offrir à son public une expérience personnelle enrichissante;

- c'est faire place à la découverte en sortant des sentiers battus et des habitudes.

Nous, organisateurs et organisatrices de fétes et d'événements, sommes des vendeurs de rêve et de bonheur. C'est une magie organisée de qualité que nous nous efforçons d'offrir!

\section{Bonne lecture}

Jacques Renaud, organisateur conseil

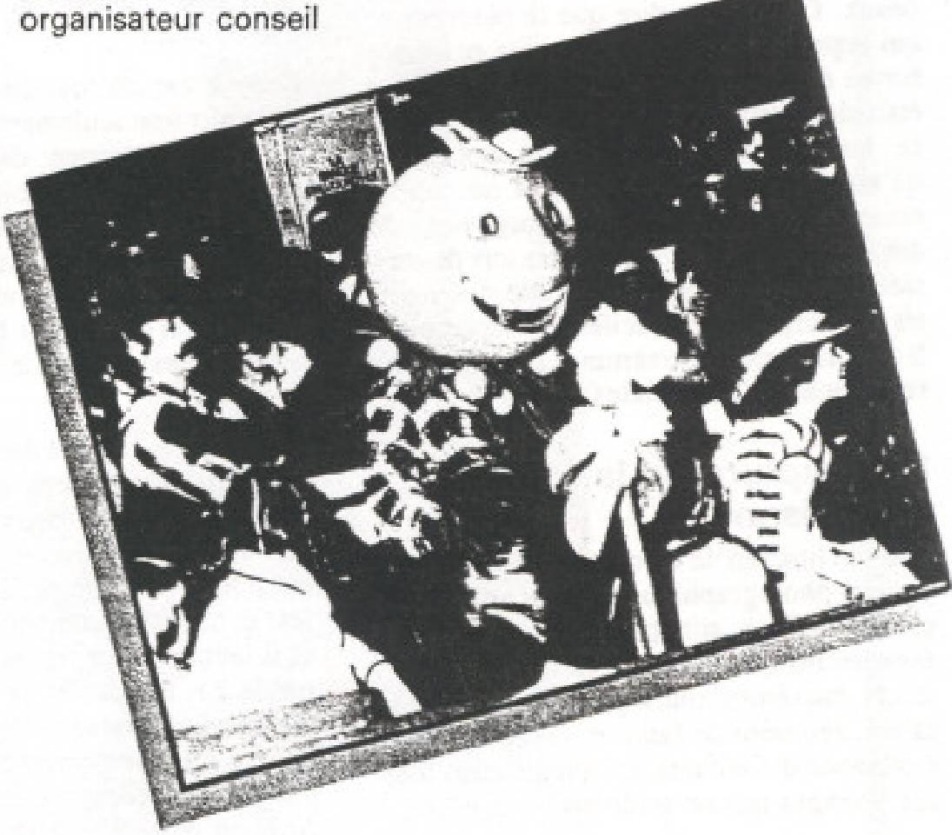

